\title{
Spatio-temporal Analysis of Rainfall Pattern in North District, Sikkim, India
}

\author{
Goutam Kumar Ghosh ${ }^{1}$, Kapil Ghosh ${ }^{2}$ \\ Former Research Scholar, Dept. of Geography \& Disaster Management, Tripura University, Suryamaninagar, India ${ }^{1}$ \\ Assistant Professor, Department of Geography, Diamond Harbour Women's University, Sarisha, India ${ }^{2}$
}

\begin{abstract}
The present study is focused on assessment and analysis of spatio-temporal variation of rainfall during last three decades (1986-2018). Rainfall data of eight rain gauge stations in North district, Sikkim have been considered for analysing. Study of rainfall depth shows that it is ranging from $925 \mathrm{~mm}$. to $3389 \mathrm{~mm}$ and ten nos. zoned has been identified. Coefficient variation (CV) of annual rainfall varies from $11.95 \%$ to $42.00 \%$ whereas the CVs of monsoonal rainfall vary from $14.87 \%$ to $49.46 \%$ which reveals that the monsoonal variability is higher than the annual variability. Rain erosivity map shows that the highest rain erosivity zone occurs in the south-eastern and southern part of the study area. There is great variation in monthly rainfall in different year and it is ranging between 100 percent negative deviation and $131 \%$ positive deviation from normal monthly rainfall.
\end{abstract}

Keywords: Rainfall, Variation, Spatio-Temporal, Rainfall Depth

\section{INTRODUCTION}

Water resource of an area is greatly controlled by the amount of precipitation. Spatial and temporal changes of steam flow, runoff, soil moisture, and groundwater reserve are the important responses to changes of rainfall pattern and quantity. Moreover, rainfall is one of the important influencing factor in various geomorphic processes in the humid tropical region of the world. The Eastern Himalaya, specially the study area (North district, Sikkim of Sikkim Himalaya), receives the high amount of rainfall (around $300 \mathrm{~cm}$.) in every year. However, there is great spatial and temporal variation in distribution of rainfall in the study area. An analysis shows that during the last two decades, total rainfall and number of rainy days has decreased in Sikkim (Bawa et al. 2012). Rahamn et al. (2012) also mention the decreasing trend of rainy days in Sikkim (Tadong station). The present study deals with the assessment and analysis of rainfall variation, distribution pattern and its erosive capacity in the study area. Spatio-temporal rainfall trend analysis leads to a better understanding of the problems associated with floods, landslide, and the availability of water for various uses with respect to future climate scenarios (Jain et al. 2013). Ayalew (1999) has observed the relationships between climatic factors such as rainfall and landslides. Climate have a dramatic influence on mass wasting events viz. heavy precipitation can initiate certain types of mass wasting by creating hydrostatic pressure and serve to lubricate slides once they are in motion. The amount of rainfall has considerable influence on the moisture content and the pore water pressure in soils. Moreover, Soil erosion is closely related to amount and intensity of rainfall through (Ghosh et al. 2013). Landslides are more likely to occur if high amounts of intense rainfall are preceded by a period of light but incessant precipitation. A high intensity of rainfall is always associated with an increase in landslides (Ghosh et al. 2012)

\section{LOCATION OF THE STUDY AREA}

North District, Sikkim is a part of inner mountain ranges of Himalayas and the largest among the four districts of Sikkim $\left(4,296\right.$ sq. km). The study area is extended between the $27^{\circ} 25^{\prime} 00^{\prime \prime} \mathrm{N}$ and $28^{\circ} 07^{\prime} 48^{\prime \prime} \mathrm{N}$ and longitudes of $88^{\circ} 03^{\prime} 00^{\prime \prime}$ E to $88^{\circ} 53^{\prime} 00^{\prime \prime}$ E (Fig. 1). Elevation of the study area ranges from $8598 \mathrm{~m}$ (Khangchendzonga) to $512 \mathrm{~m}$ (near Dikchu) and the area is mostly hilly tract and maximum area $\left(2287 \mathrm{Km}^{2}\right)$ of the district shows very steep slope $\left(60^{\circ}\right.$ $80^{\circ}$ ). Geologically, the present study area is characterized by young folded mountains and falling in earthquake zone V. The North Sikkim district experiences humid climates with seasonally intense rainfall. Annual rainfall tends to increase from north-west to south-east. It is apparent that the average annual rainfall varies from $925 \mathrm{~mm}$ to $3389 \mathrm{~mm}$. The northern most part of the district is covered with dense snow, which feed the major river systems of the district. About $46.13 \%$ of the district is under snow covered area or glacier or Alpine barren. A number of glaciers descend from the eastern slopes of Khangchendzonga, where show line is found above 5,300 m. The river Tista and its tributaries mainly drain the district. About $60 \%$ of the total geographical area of Sikkim is cover by North Sikkim district but it accounts only $7.13 \%$ of the state's population with density of 10 persons per sq. $\mathrm{km}$. whereas the state has 86 persons per sq. $\mathrm{km}$ (Census 2011). 


\section{International Advanced Research Journal in Science, Engineering and Technology}

Vol. 6, Issue 5, May 2019

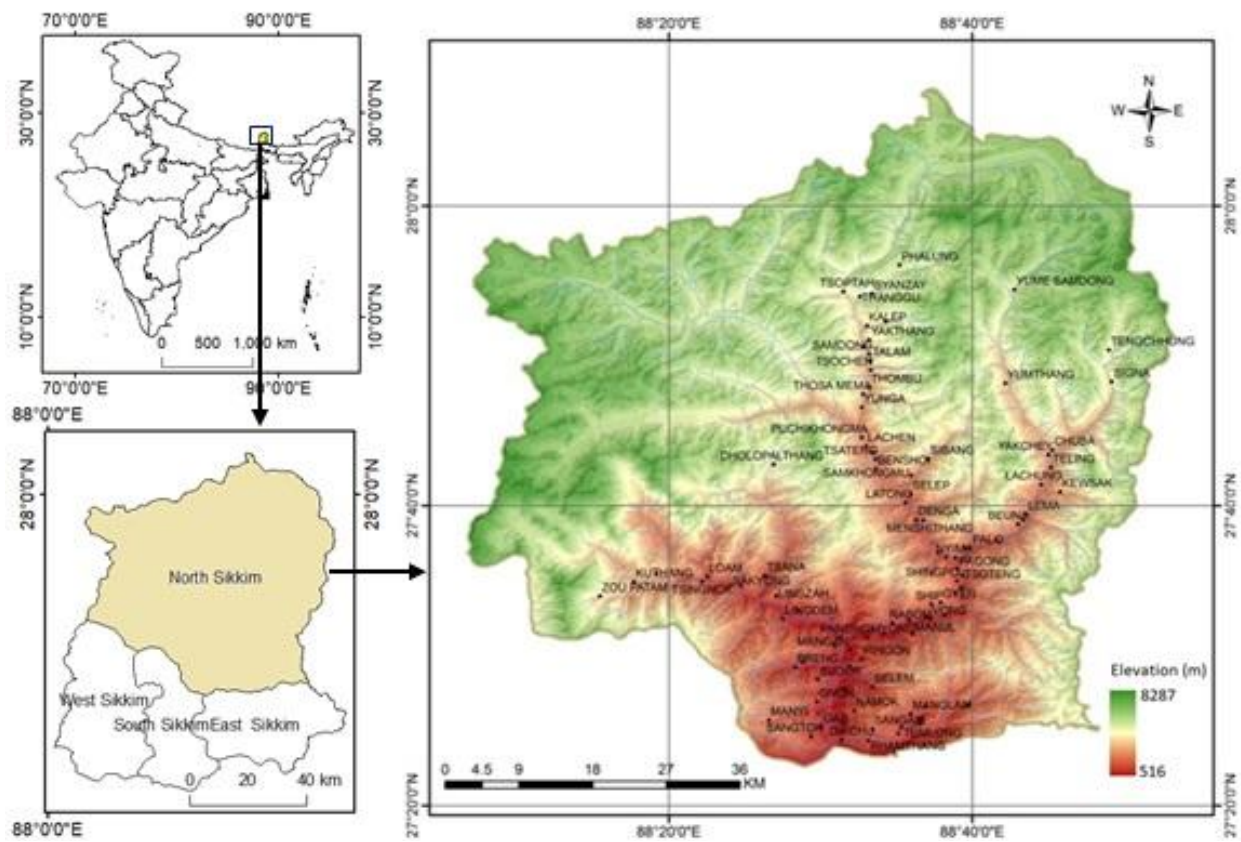

Figure 1: Location of the study area with Digital Elevation Model.

\section{MATERIALS AND METHODS}

Rainfall characteristics of the study area has been analysed by considering eight rain gauge stations (Dikchu, Singhik, Chungthang, Lachung, Yumthang, Lachen, Mangan, Thanggu) located within the study area. The distance between two stations is not always uniform due to their overall locational disadvantage. Moreover, the rainfall data for all the stations are not available for equal number of years. Monthly rainfall variation in north Sikkim distract during 20112018 have been analysed by considering arithmetic average of monthly rainfall of all stations. This data are obtained from Hydrome division of Indian Meteorological Department, New Delhi. The rainfall data of selected stations have been processed and analyzed to predict quantitatively: The nature of distribution of annual rainfall depth, variability of rainfall (annual and monsoon), rainfall trends and rainfall erosivity.

A. Rainfall Depth: The Isohytal method is used to analyse the average depth of rainfall over the North district, Sikkim. This method is more applicable in region where orographic effect is observed (Linsley, Kohler and Paulhus, 1949). Based on the point rainfall data a number of isohytes have been drawn to find out the zones having different ranges of mean annual rainfall depth. The average value of each zone is calculated by compiling the mean value of the incremental amount between each pair of isohytes encompassing a particular zone. The individual average depth of rainfall of each zone has been weighted by the respective areas occupied by them. Finally, the total of their weighted values has been divided by the total area of the study area to get the average annual precipitation of the whole study area. The formula used in rainfall depth calculation is given below:

$$
\bar{P}=\frac{1}{A}{ }_{j=1}^{J} \frac{A_{j}}{P_{j}}
$$

Where, $\bar{P}=$ Average annual precipitation, $\quad \mathbf{A}={ }_{j=1}^{J} A_{j}$, i.e. the total area computed by adding the individual zones, $P_{j}=$ Average annual precipitation of the $\mathrm{j}$ zone, $\mathrm{J}=$ Total number of zones

B. Rainfall Variability: To calculate the co-efficient of the variability of rainfall of different rain-gauge stations of the study area, the following method has been used (Williamson and Clark, 1931):

$$
C V=\frac{\sigma_{p}}{\bar{P}} \times 100
$$

Where, $C V=$ Co-efficient of variability, $\quad p=$ Standard deviation of rainfall, $\bar{P}=$ Mean rainfall 


\title{
International Advanced Research Journal in Science, Engineering and Technology
}

\author{
Vol. 6, Issue 5, May 2019
}

C. Rainfall Erosivity: Rain erosivity (R) is calculated as a product of storm kinetic energy (E) and the maximum 30 minutes rain fall intensity. This relationship (Wischmeier \& Smith 1978) helps to quantify the impact of rain drop over a piece of land and the rate of runoff associated with the rain. But till now that kind of detailed meteorological data is not available for all the stations in the study area. Therefore, Equation given by Singh et al. (1981) has been used for estimating annual $\mathrm{R}$ factor. $\mathrm{R}$ Factors data of these eight stations were imported into ArcGIS 9.3 and interpolation method was used.

$$
\mathrm{R}=79+0.363 * P
$$

Where, $\mathrm{R}$ is the annual Rain erosivity factor, $\mathrm{P}$ is the annual Rainfall in $\mathrm{mm}$.

\section{RESULT AND DISCUSSION}

A. Rainfall Depth: Average depth of rainfall is an important technique to find out the average amount of rainfall accumulation over an area. The weighted values of the average rainfall depth of each zone as well as the average annual precipitation of the whole study area are shown in the Table 1. It is apparent from the Table 1 that the study area is consisted of ten average annual rainfall depth zones and the values range from $925 \mathrm{~mm}$. to $3389 \mathrm{~mm}$. The aforesaid rainfall depth zones have further been categorized on the basis of the average annual rainfall of the whole study area (Table 1).

Table 1: Rainfall Depth Zone under different categories

\begin{tabular}{|c|c|c|c|}
\hline Depth Zone & Depth Zone Range & Average rainfall in $\mathrm{mm}$ & Categories \\
\hline I & $<1050$ & 925 & Very Low \\
\hline II & $1050-1300$ & 1175 & \\
\hline III & $1300-1550$ & 1425 & Low \\
\hline IV & $1550-1800$ & 1690 & \\
\hline $\mathrm{V}$ & $1800-2050$ & 1885 & Moderate \\
\hline VI & $2050-2300$ & 2175 & \\
\hline VII & $2300-2550$ & 2425 & High \\
\hline VIII & $2550-2800$ & 2710 & \\
\hline IX & $2800-3050$ & 2925 & Very High \\
\hline $\mathrm{X}$ & $>3050$ & 3389 & \\
\hline
\end{tabular}

To categorize the average rainfall depth zones, the average annual precipitation of the whole study area has been taken into consideration. Low rainfall depth zone has been determined considering the values those exist far more below the average value of the whole study area. There are ten rainfall depth zones, which are subdivided again five categories viz. very low, low, moderate, high, and very high depth zone. The rainfall depth zone map indicates that the Mangaon areas exist in the highest rainfall depth zone. From this zone the rainfall depth gradually decreases towards the northern and southern sides. The very lowest rainfall depth is found towards the extreme northwestern part of the study area. The moderate rainfall depth zone mainly is found in the southern portion of highest rainfall depth zone of the study area (Figure 2).

Regarding the areal distribution of different rainfall depth categories, the highest area $\left(868.5 \mathrm{~km}^{2}\right)$ occupied by the zone IV (1550-1800) which consist $1690 \mathrm{~mm}$ average annual rainfall, the second highest area $\left(599.22 \mathrm{~km}^{2}\right)$ occupied by the zone V (1800-2050) which consist $1885 \mathrm{~mm}$ average annual rainfall, and the lowest area $\left(111.7 \mathrm{~km}^{2}\right)$ occupied by the zone I $(<1050)$ which consist $925 \mathrm{~mm}$ average annual rainfall whereas the highest average annual rainfall $(3389 \mathrm{~mm})$, e.g. the zone X (>3050) occupied only $397.03 \mathrm{~km}^{2}$.

B. Rainfall Variability: Rainfall variability of an area has a great importance to find out the role of rainfall in shaping the physical as well as socio-economic aspects of a particular area. Landform configuration depends on the variability of rainfall to a great extent. Since, the study area belongs to the monsoon climatic region; therefore, monsoonal rainfall variability has also great importance parallel with the annual rainfall variability. Thus, both annual and monsoonal rainfall variability has been taken into consideration to find out their individual role in influencing the fluvial dynamics of the study area. The mean, the standard deviation of rainfall in $\mathrm{mm}$ and the co-efficient of variability in percentage of annual as well as monsoonal rainfall of eight rain-gauge stations are shown in Table 2.

On the basis of the calculated values of the rainfall station CVs the annual and monsoonal rainfall variability maps have been drawn. From Table 3 it is observed that the CVs of annual rainfall vary from $11.95 \%$ to $42.00 \%$ whereas the CVs of monsoonal rainfall vary from $14.87 \%$ to $49.46 \%$. Analysis of annual and monsoon rainfall variability reveals that the monsoon variability to higher than the annual variability. This fact depicts the common character of monsoon wind, which is prevalent in the study area. 
International Advanced Research Journal in Science, Engineering and Technology

Vol. 6, Issue 5, May 2019

Table 2: Co-efficient variability of annual and monsoonal rainfall

\begin{tabular}{|l|l|l|l|l|l|l|l|}
\hline $\begin{array}{l}\text { SI } \\
\text { No }\end{array}$ & $\begin{array}{l}\text { Rain Gauge } \\
\text { Station }\end{array}$ & $\begin{array}{l}-\mathbf{P} \text { in } \\
\mathbf{m m}\end{array}$ & $\begin{array}{l}\text { Annual Rainfall } \\
(\boldsymbol{\sigma} \text { in mm })\end{array}$ & $\mathbf{C V}$ in \% & $\begin{array}{l}-\mathbf{P} \text { in } \\
\mathbf{m m}\end{array}$ & $\begin{array}{l}\text { Monsoonal } \\
\text { Rainfall }(\boldsymbol{\sigma i n} \mathbf{~ m m})\end{array}$ & $\mathbf{C V}$ in \% \\
\hline 1 & Dikchu & 3385.76 & 404.7094 & 11.95328 & 2586.287 & 698.7448 & 27.0172 \\
\hline 2 & Singhik & 3519.485 & 1181.467 & 33.56933 & 2473.125 & 772.5740 & 31.2387 \\
\hline 3 & Chungthang & 2749.05 & 917.6024 & 33.37883 & 2049.77 & 744.6940 & 36.3306 \\
\hline 4 & Lachung & 1741.54 & 317.7207 & 18.24361 & 1220.21 & 232.7046 & 19.0707 \\
\hline 5 & Yumthang & 1411.47 & 212.5197 & 15.05662 & 1099.55 & 163.5908 & 14.8779 \\
\hline 6 & Lachen & 1615.88 & 556.8396 & 34.46034 & 1214.99 & 320.8935 & 26.41121 \\
\hline 7 & Thangu & 768.58 & 322.8643 & 42.00790 & 497.905 & 113.4591 & 22.7873 \\
\hline 8 & Mangan & 2983.46 & 726.0064 & 24.33438 & 2378.60 & 1176.535 & 49.4633 \\
\hline
\end{tabular}

Table 3: Different zones of annual and monsoon rainfall variability

\begin{tabular}{|c|c|c|c|c|c|c|}
\hline & \multicolumn{3}{|c|}{ Annual } & \multicolumn{3}{|c|}{ Monsoon } \\
\hline $\begin{array}{l}\text { Serial } \\
\text { No. }\end{array}$ & zone & Area $\left(\mathbf{k m}^{2}\right)$ & Area (\%) & zone & Area $\left(\mathbf{k m}^{2}\right)$ & Area (\%) \\
\hline 1 & $>35$ & 702.29 & 16.35 & $>40$ & 49.57 & 1.15 \\
\hline 2 & $30-35$ & 1078.97 & 25.12 & $35-40$ & 334.47 & 7.78 \\
\hline 3 & $25-30$ & 1335.53 & 31.09 & $30-35$ & 1000.98 & 23.3 \\
\hline 4 & $20-25$ & 662.68 & 15.42 & $25-30$ & 1095.81 & 25.51 \\
\hline 5 & $15-20$ & 480.39 & 11.18 & $20-25$ & 1364.03 & 31.75 \\
\hline 6 & $<15$ & 36.14 & 0.84 & $<20$ & 451.14 & 10.51 \\
\hline
\end{tabular}

Figure 3 regarding the annual rainfall variability, the whole study area can be divided into six distinct variability zones at $5 \%$ interval in coefficient of variation. Among the six zones the maximum area $\left(1335.53 \mathrm{~km}^{2}\right)$ occupied by the zone III (25-30\%), the second highest on the basis of occupied area is zone II, which occupied $1078.97 \mathrm{~km}^{2}(25.12 \%)$ and very least occupied category is the zone VI $\left(<15 \%\right.$ ) which occupied only $36.14 \mathrm{~km}^{2}$ (Table 3 ). Figure 4 shows the monsoon rainfall variability the whole study area can be divided into six distinct variability zones at $5 \%$ interval in coefficient of variation. Among the six zones the maximum area $\left(1364.03 \mathrm{~km}^{2}\right)$ occupied by the zone V $(20-25 \%)$, the second highest on the basis of occupied area is zone IV, which occupied $1095.81 \mathrm{~km}^{2}(25.51 \%)$ and very least occupied category is the zone I (> 40\%) which occupied only $49.57 \mathrm{~km}^{2}$ (Table 3 ). So, the monsoonal rainfall variability pattern is different from the annual variability. The distribution pattern is almost the same as in the annual rainfall variability. The only difference is noticed that the highest annual rainfall variability is found in the zones III \& II whereas the highest monsoonal rainfall variability is found in the zones V \& IV respectively.

\section{Rain Erosivity}

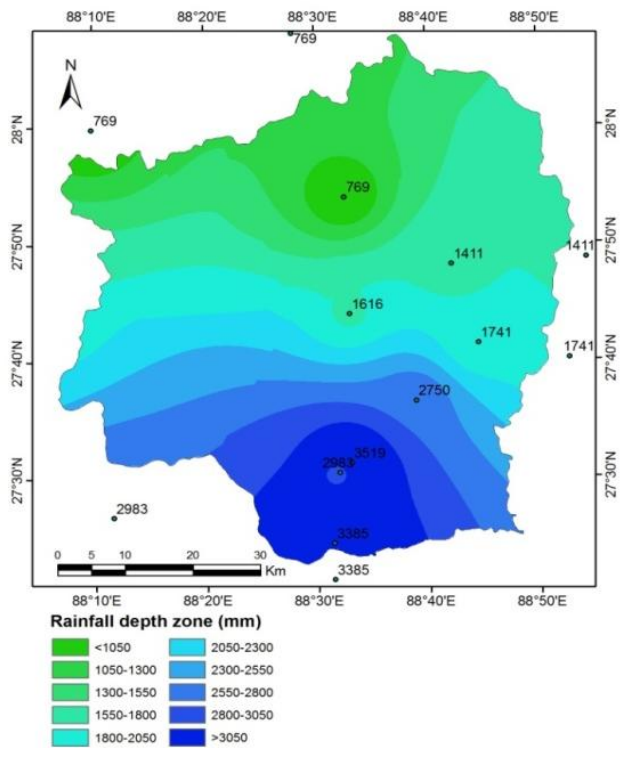

Figure 2: Rainfall depth zone map of the North district, Sikkim

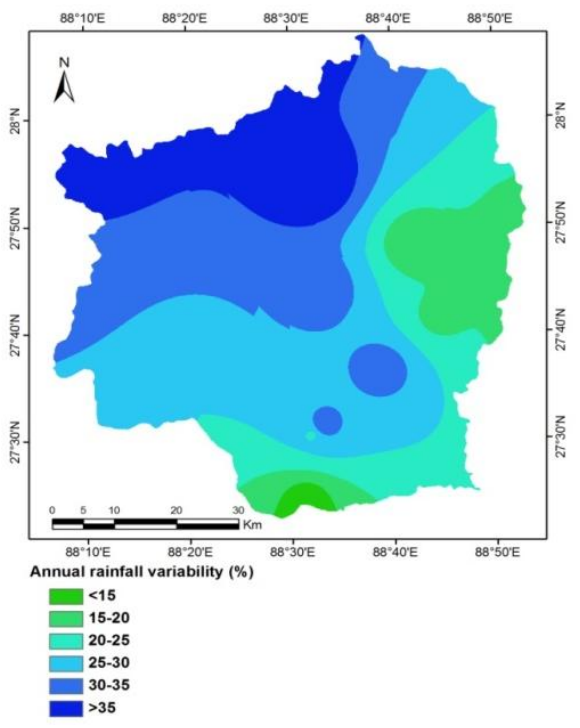

Figure 3: Annual rainfall variability map of the North district, Sikkim 


\section{International Advanced Research Journal in Science, Engineering and Technology}

Vol. 6, Issue 5, May 2019

The rainfall Erosivity $(\mathrm{R})$ is the product of kinetic energy $(\mathrm{E})$ of the storm and its maximum 30-minute intensity and s called the Rainfall Erosion Index (EI) (Smith and Wischmeier, 1962). An iso-erodent map of the study area has been prepared on the basis of the calculated $\mathrm{R}$ indices and their overall characteristics have been depicted below. Rain erosivity values are ranging from 358 tons/ha/year to 1355.86 tons/ha/year. It is observed from the rain erosivity map (Figure 5) that the highest rain erosivity zone occurs in the south-eastern and southern part of the study area and decreases gradually to the north, north-western part of the study area. The lowest erosivity zone occurs in and around the Thangu in the extreme northern part of the study area.

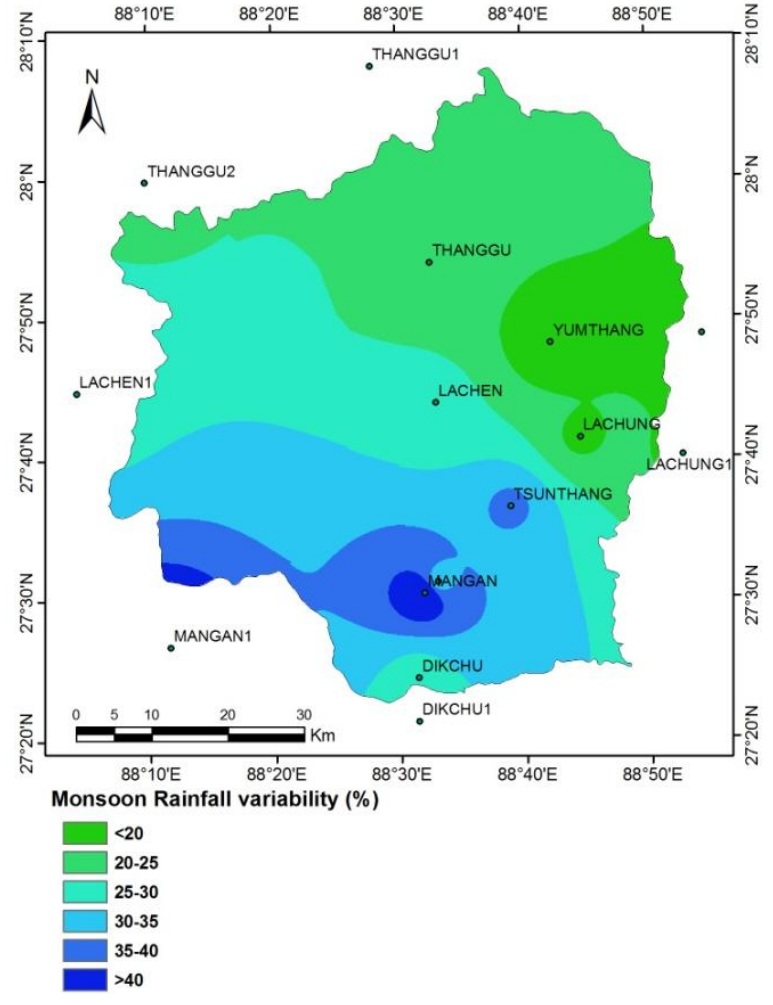

Figure 4: Monsoon rainfall variability map of the North district, Sikkim

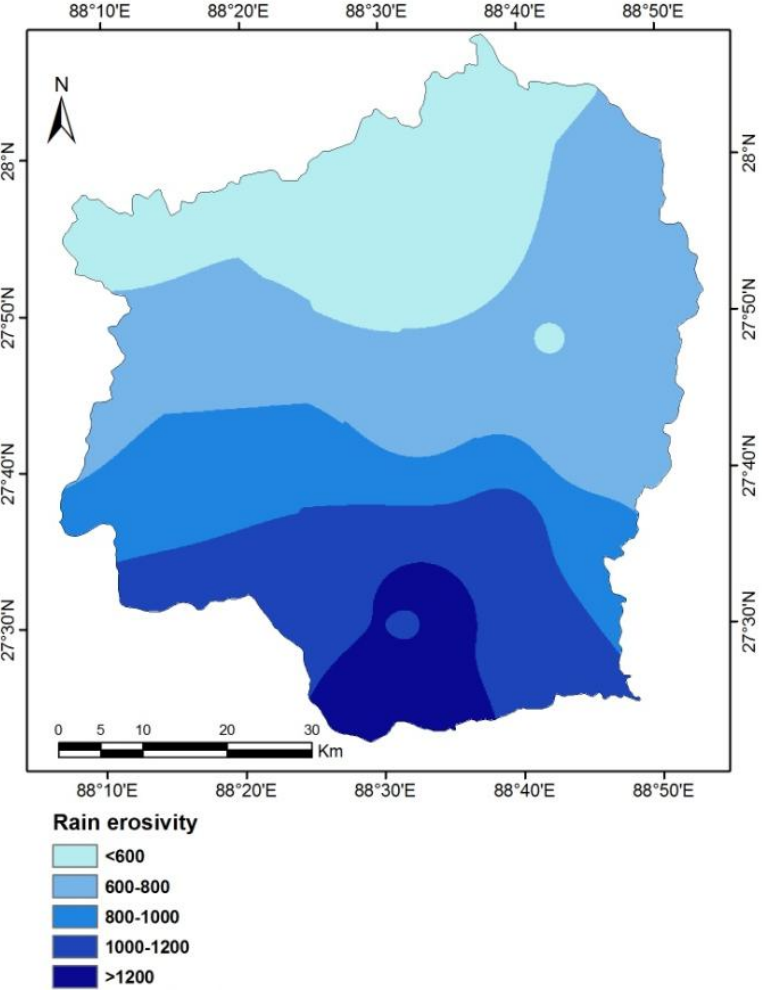

Figure 5: Rainfall erosivity map of the North district, Sikkim

D. Monthly Rainfall Variation

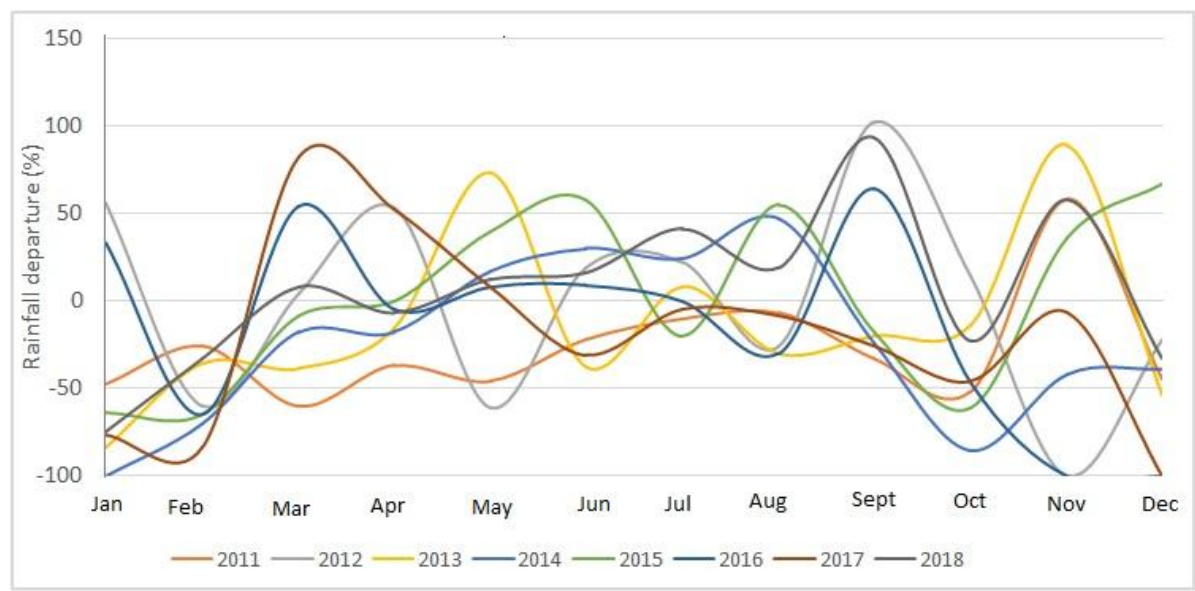

Source: Hydrome division, IMD, New Delhi

Figure 6: Monthly rainfall variation in North district, Sikkim during 2011-2018. 


\title{
International Advanced Research Journal in Science, Engineering and Technology
}

\author{
Vol. 6, Issue 5, May 2019
}

The present study area is falling in south-west monsoon climate. Rainfall in monsoon regime is highly variable in both time and space. In order to understand the uncertainty and variability over time in North district, deviation of monthly rainfall has been taken into consideration. During 2011-2018, it is found there are great variations in monthly rainfall in different months in a year as well as in same month during different years (Figure 6). In the year 2008, negative deviation was found in January, February, April, October and December whereas, others months shows positive deviation from its normal monthly rainfall amount. Rainfall occurred in May during 2011-2018 shows that in 2011 ($46 \%$ ) and 2014 (-61) received lass amount of rainfall where as in 2013 (74\%), 2014 (17\%), 2015(40\%) 2016(8\%), $2017(8 \%) 2018(12 \%)$ received more amount of rainfall. Maximum positive deviation (131\%) was found in the month of December in 2011 and maximum negative deviation (-100\%) was found in November 2012 and January 2014.

\section{CONCLUSION}

The Rainfall data of eight rain-gauge station and in North district have been taken into consideration for the analysis of rainfall characteristics of the study area. Annual rainfall of the present study area varies from $925 \mathrm{~mm}$ to $3389 \mathrm{~mm}$. The annual rainfall distribution shows that it is heavier in the Southern part and gradually decreases towards north and North-east. The present study reveals that there are significant spatial and temporal variations in rainfall. The rainfall depth zone map indicates that very lowest rainfall depth is found towards the extreme north-western part of the study area. Coefficient variability (\%) of annual rainfall shows that the maximum area $\left(1335.53 \mathrm{~km}^{2}\right)$ is occupied by the high zone $(25 \%-30 \%)$ which reveals that large part of the study area depict highly inconsistence rainfall occurrence. From the analysis of rainfall variability it is clearly noticed that the consistency of annual rainfall is higher than that of monsoonal variability, because the coefficient value of monsoonal rainfall variability is higher (i.e. 49.46\%) than that of the coefficient of annual rainfall variability (i.e. $42.00 \%$ ). The difference between the highest and lowest coefficients of monsoonal rainfall variability is higher (i.e. 34.59\%) than that of annual rainfall variability (i.e. 30.05\%). Thus, the variation of occurrence of monsoonal rainfall is higher than that of annual rainfall. From the analysis of monthly rainfall deviation, it is found that the deviation during non-monsoon months is greater than the monsoon months.

Analysis of various aspect of rainfall can help to understand its association with cropping pattern, role in different geomorphic process and disaster preparedness plan in the study area.

\section{REFERENCES}

[1]. L. Ayalew, "The effect of seasonal rainfall on landslides in the highlands of Ethiopia" Bulletin of Engineering Geology and Environment, Vol. pp.58, pp. 9-19, 1999

[2]. K. S. Bawa, T. Ingty, "Climate change in Sikkim: A synthesis". In Arrawatia, ML, Tambe S (Eds), Climate Change in Sikkim Patterns, Impacts and Initiatives, Information and Public Relations Department, Government of Sikkim, pp 413-424, 2012

[3]. District Census handbook, Census of India, 2011

[4]. K. Ghosh, S. Bandyopadhyay, S. K. De, "Landslide Susceptibility Zonation Using Weight Rating Based Method in GIS: A Case Study in Dhalai District, Tripura", Indian Journal of Geomorphology, Vol. 17(2), pp. 127-145, 2012

[5]. K. Ghosh, S. K. SK, S. Bandyopadhyay, S. Saha, “Assessment of Soil Loss of Dhalai River Basin, Tripura, India using USLE”, International Journal of Geosciences, Vol. 4(1), pp.11-23, 2013

[6]. S. K. Jain, K. Vijay, M. Saharia, "Analysis of rainfall and temperature trends in northeast India", International Journal of Climatology, Vol. 33, pp. $968-978,2013$

[7]. R. K. Linsley, M.A. Kohler, J. L. H. Paulhus, "Applied Hydrology”, Mc. Graw Hill Book Company, USA, p.689, 1949

[8]. H. Rahman, R. Karuppaiyan, P. C. Senapati, S. V. Ngachan, A. Kumar, "An Analysis of Past Three Decade Weather Phenomenon At The Mid-Hills Of Sikkim And Strategies For Mitigating Possible Impact Of Climate Change On Agriculture", In Arrawatia ML, Tambe S. (Eds.), Climate Change in Sikkim Patterns, Impacts and Initiatives, Information and Public Relations Department, Government of Sikkim, pp 19-48, 2012

[9]. G. V. V. Singh, Rambabu and S. Chandra, "Soil Loss Prediction Research in India", ICAR Bullet, T12/D9, CS WCTRI, Dehradun, 1981

[10]. D. D. Smith, and W. H. Wischmeier, "Rainfall erosion", Advances in Agronomy, Vol. 14, pp. 109-148, 1962

[11]. A. V. Williamson and K. G. T. Clark, "The variability of the annual rainfall of India”, Quarterly Journal of the Royal Meteorological Society, Vol. 57, pp. 43-56, 1931

[12]. W. H. Wischmeier and D. D. Smith, "Predicting rainfall erosion loss: a guide to conservation planning", US Department of Agriculture, Agricultural Research Service, Washington, DC, Agricultural Handbook, No. 537, 1978 